meeting was held, which heard the paper with interest.

The meetings of the section were well attended all through, and on several occasions the room, although holding 350 people, was not large enough for those who desired to hear certain papers. The programme was too crowded, and there was not sufficient time for discussion. The remedy is in the sectional committee's own hands. Two afternoon sessions in the week would remove all congestion, and it is difficult to see why Section A should not adopt a course followed by several other sections. This course was urged by the Recorder at the Committee, but rejected. The experiment of a discussion of a particular paper-Prof. Bragg's-in the afternoon was a complete success, and to hold such afternoon meetings would be a better method than to restrict the number of papers contributed. It would be a loss to the usefulness of the section if less important papers were altogether crowded out. One function of the association is to provide some opportunity and encouragement to younger and less well known men, and it would be a pity for such a function to be lost altogether.

Some important work was done in the sectional committee and in research committees. The report ot the Seismological Committee has been already referred to. The Seismological Committee had to consider what steps should be taken in order to carry on the work that has hitherto been done under Prof. Milne. It was felt that it was impossible to raise enough money to carry on the work at Shide as an independent station, and the committee decided to try to obtain sufficient funds to enable the observational work to go on. Prof. H. H. Turner undertook to exercise a general supervision over the station at Shide, and for the present this seems a satisfactory arrangement. But it is unfortunate that the work cannot be carried on with proper equipment and personnel. Seismology owes so much to Milne that it would be a fitting tribute to his memory for his observing station to develop into a thoroughly equipped institution. In the meantime, the subject is under great obligation to Prof. Turner for taking over the general supervision.

A report was received from the Electrical Standards' Committee announcing its own dissolution. This committee has done immensely important service in the past. Its work has appeared in a more readily obtainable form. The reports from $\mathrm{r} 86 \mathrm{r}$ to the present time are republished in one volume. Prof. H. H. Turner moved a resolution calling attention to the historic character of this committee, and expressing on behalf of the Committee of Section A the sense of its importance and value. Dr. Glazebrook, the secretary of the Standards' Committee, replied.

An important research committee on radiotelegraphic investigations presented its first report and outlined a programme of work. Certain problems, especially those of "strays" and of the differences between night and day signalling, can only be investigated by cooperative work at widely scattered stations. The committee has obtained the cooperation of most of the large institutions connected with wireless telegraphy, and hope that exceedingly valuable work may be done in the near future. Both this committee and the seismological committee hope to be able to carry on their work by means of grants from the Caird Fund.

Reports were also received from the committees for investigation of the upper atmosphere, for the tabulation of Bessel and other functions, for the establishment of a solar observatory in Australia, for administering a grant for the international tables of constants, and for the disposal of "the binary canon."
The list of grants made to research committees has already appeared in the columns of NATURE.

The local arrangements for the meeting of the section were admirable. The rooms devoted to Section A were in the Mason College, and served their purpose excellently. The large room on some occasions was not quite large enough, but it would be difficult to find anywhere a suitable lecture-room to hold the number who would have liked to hear some of the papers. Great credit is due to those who had the arrangements in hand, especially to Dr. Shakespear, for the smooth working of such a large and complicated section. A word of congratulation may also be given to The Times for the excellent way in which some of the meetings, especially the radiation discussion, were reported.

\section{UNIVERSITY AND EDUCATIONAL.} INTELLIGENCE.

Birmingham.-A course of ten lectures on social anthropology, by Mr. A. R. Brown, of Trinity College, Cambridge, has been arranged for the winter and spring terms. This course is the outcome of a suggestion made in the Anthropological Section of the British Association during the recent meeting, and is intended as a tentative experiment to determine to what extent there is a demand for such a course in addition to the existing course in physical anthropology.

Cambridge.-Mr. W. E. Hartley, of Trinity College, has, with the consent of the Vice-Chancellor, been appointed chief assistant at the observatory.

Mr. F. W. Aston, of Trinity College, has been elected to the Clerk Maxwell scholarship.

Mr. 'T. L. Wren and Mr. F. Kidd have been elected to fellowships at St. John's College.

An examination for the award of the Sheepshanks astronomical exhibition will be held in the Lent term, roI4. The exhibition is open to all undergraduates of the University of Cambridge, but any person elected, if not already a student of Trinity College, shall thereupon become a student of Trinity College. Candidates may offer themselves for examination in one or more of the following subjects:-(a) astronomy and allied subjects as defined in Schedule A of part ii. of the mathematical tripos; $(b)$ spherical astronomy and combination of conservations; (c) celestial mechanics; $(d)$ use and optical theory of astronomical instruments; (e) astrophysics. A paper of essays on astronomical subjects and an examination at the observatory in elementary practical astronomy will be compulsory on all candidates.

AMONG numerous bequests under the will of the late Dr. F. G. Smart is one of " $10,000 l$. to Gonville and Caius College, Cambridge, for two 'Frank Smart Studentships, in natural history or botany, and if this sum shall be more than sufficient to provide for these studentships the balance is to be used to promote the study of these subjects in that college."

Mr. J. A. Pease, President of the Board of Education, speaking at Camberwell on October 3I, forecasted largely increased grants from the Treasury for education. In the course of his remarks he said :"Local authorities know only too well that educational expenditure has increased and is increasing, and I must tell them that it will have to increase still farther if we are to get the economic equivalent for what we spend. The gravest of all defects in our educational system is not in elementary education, but in intermediate education. Every child in the country has an equal chance of developing his abilities up to a certain point. It is when that point is reached and passed 
that the defects of our present system make themselves manifest. You keep a child at school for eight or nine years, and just at the critical time when his natural aptitudes are taking their bent and his character is forming his education is broken off, and the boy and the girl who might have done good service in some profession or skilled industry drops into idleness or loafing, or adds one to the millions of casual and unskilled labourers. I say with conviction that the first upward step must be the improvement of our intermediate education, because that is the branch in which we are most lacking. You may not always find a genius - a genius is rare-but remember that if you do find him you will have repaid yourselves more than a hundredfold. Remember the economic value of a great inventor covers the educational expenditure of a whole town. I think Sir Henry Bessemer was a fellow-townsman of yours here in Camberwell, and Sir Henry Bessemer's chief invention, we know, was equal in productive power to the labours of a hundred thousand men. Now, that is why I say that we must be prepared for further expenditure if we are to get the economic equivalent for what we have spent already. We must be prepared as a country to foot the bill, just as the Government will be prepared to make the proposals to the country. The Government policy is a large policy, and I may say that it is our intention not only to increase the amount of the grant, but to change the manner of its distribution, so that of two areas equally $\epsilon$ fficient the poorer will receive the larger grant, and of two areas equally necessitous the more efficient will receive the larger grant."

A suggestive paper was read by Mr. Cloudesiey Brereton at a conference of employers of labour on October 28, in connection with the recent National Gas Congress and Exhibition. Mr. Brereton pointed out that although until recently education in England has busied itself far too little, upon the whole, with the problems of the work-a-day world, yet even the older English Universities of Oxford and Cambridge in actual practice have always been to a considerable extent technological institutions. Their work has been mainly, not so much the imparting of book knowledge, but of "mancraft," the art of handling men, gained through daily contact with their fellows. In so far as the studies of candidates for theology, medicine, and law are concerned, these Universities are to all intents and purposes purely technological colleges. At the present time in the older, and to a far greater extent in the younger, universities we find training in technique provided in many subjects, not merely in law, medicine, and theology, but also in engineering, applied chemistry, the textile industries, gas and electricity, and certain branches of commerce. Whatever the grade of educational institution may be the problem of suitable curricula can only be solved by first considering what will be the probable career of the pupil. The elementary school is already moving in the direction of first diagnosing the pupil's future needs and then prescribing for him. Even the older universities and the public schools are showing signs of being affected by similar influences. Employers, in consequence of the increasing pressure of competition and the invasion of industry by science, are as vitally interested in the production of pupils of the right type as the educationist is, or ought to be. Mr. Cloudeslev Brereton gave a valuable summary of the principal steps which have been taken by employers to foster the continued education of their employees, e.g. by the award of prizes for attendance and success at examinations, the payment or repayment of fees, making attendance at evening classes compulsory upon junior emiployees, meetings at works during the hours of employment, and the formation of advisory committees NO. 2297, voL. 92] containing representatives of employers and workmen. Important educational results are accruing from such organised schemes of training as those at Sunderland for engineering apprentices, and at the Bournville works. With regard to the question of raising the age of attendance at school to sixteen or seventeen, he suggested that one great difficulty, apart from the cost, is the growing dissatisfaction with the mainly literary type of education, and the conviction that our present system does not give value for the public money now granted.

At the distribution of prizes to successful students of the City and Guilds Institute at the Mansion House on October 29, the President of the Board of Education delivered an address. Mr. Pease dealt with the question of a worthy university for London. He said that the Government, after careful consideration, has decided that the scheme set out in the report of the recent Royal Commission is calculated to produce a University of London worthy of the name. Everything possible is to be done to carry out the scheme with all reasonable dispatch. To this end a Departmental Committee has been appointed. The underlying principles of the Commission's scheme are to be regarded as accepted. Modifications in detail and machinery may be found desirable, but the fundamental principles must be accepted if any advance is to be made now. If London shows that it is anxious and willing to have a reconstituted University on the lines laid down in the report of the Royal Commission, the Government will play their part in supplying the money necessary. Continuing, Mr. Pease said:-_" The whole history of the development of modern universities shows that the prime essential of success is local patriotism. Local patriotism means, of course, money, but it means a great deal more besides. It implies a belief in the necessity for a great university and in the immensity of the influence the university can exercise-an influence which, especially in the case of an Empire metropolis, must always extend far beyond the narrow limits of the area which the university primarily serves. Its functions will be Imperial, even international, as well as local. But without the active support and confidence of the locality no modern university can exist, let alone flourish. Acts of Parliament and State-aid cannot alone create a university." In the case of the University of London, Mr. Pease laid it down that the principles on which any permanently satisfactory scheme must be based are simple:-(1) Educational and financial control of all the most important colleges to be in the hands of the University; (2) the creation of a Universitv quarter by concentration of as much of the University work as possible, together with its administration, on a central site [the Imperial College must remain where it is]; (3) government of the University by a small Senate, predominantly lay, and not representative of special interests; (4) control of the teaching and examination in the hands of the teachers; (5) continuance of access to University examinations by external students. The place of the Imperial College in a reconstituted University is one of the first points the Departmental Committee proposes to investigate.

\section{SOCIETIES AND ACADEMIES.}

Cambridge.

Philosophical Society, October 27.- Prof. Hobson in the chair.-R. D. Kleeman: The dependence of the relative ionisation in various gases by $\beta$ rays on their velocity, and its bearing on the ionisation produced by $\gamma$ rays. - N. P. Mccleland : Note on a dynamical system illustrating fluorescence. 